\title{
"Mothers as Candy Wrappers": Critical Infrastructure Supporting the Transition into Motherhood
}

\author{
LAUREN BRITTON, Ithaca College, NY, USA \\ LOUISE BARKHUUS, The IT University of Copenhagen, Denmark \\ BRYAN SEMAAN, Syracuse University, NY, USA
}

\begin{abstract}
The transition into motherhood is a complicated and often unsupported major life disruption. To alleviate mental health issues and to support identity re-negotiation, mothers are increasingly turning to online mothers' groups, particularly private and secret Facebook groups; these can provide a complex system of social, emotional, and practical support for new mothers. In this paper we present findings from an exploratory interview study of how new mothers create, find, use, and participate in ICTs, specifically online mothers' groups, to combat the lack of formal support systems by developing substitute networks. Utilizing a framework of critical infrastructures, we found that these online substitute networks were created by women, for women, in an effort to fill much needed social, political, and medical gaps that fail to see 'woman and mother' as a whole being, rather than simply as a 'discarded candy wrapper'. Our study contributes to the growing literature on ICT use by mothers for supporting and negotiating new identities, by illustrating how these infrastructures can be re-designed and appropriated in use, for critical utilization.
\end{abstract}

\section{CCS Concepts: • Human-centered computing $\rightarrow$ Computer supported cooperative work}

\section{KEYWORDS}

Social media groups; motherhood; transition; ICTs.

\section{ACM Reference format:}

Lauren Britton, Louise Barkhuus, and Bryan Semaan. 2019. "Mothers as Candy Wrappers": Critical Infrastructure Supporting the Transition into Motherhood. In Proceedings of the ACM on Human-Computer Interaction, Vol. 3, GROUP, Article 232 (December 2019), 20 pages, https://doi.org/10.1145/3361113

\section{INTRODUCTION}

Life disruptions can take on many forms-for example, being diagnosed with a disease, becoming homeless, or experiencing job loss [17] Opposed to most types of life disruptions, becoming a mother is a life disruption that happens to almost all women at one point in their lifetime. Motherhood is experienced by $86 \%$ of women in the United States, meaning this is a major life disruption and transition that impacts a substantial portion of the United States population at one point or another. Following a life disruption, people often undergo a period of adjustment, referred to as a transition [1]. To successfully transition, and thus adjust to a life disruption, people often engage in re-negotiation work through which they must re-structure key aspects of their lives,

Permission to make digital or hard copies of all or part of this work for personal or classroom use is granted without fee provided that copies are not made or distributed for profit or commercial advantage and that copies bear this notice and the full citation on the first page. Copyrights for components of this work owned by others than ACM must be honored. Abstracting with credit is permitted. To copy otherwise, or republish, to post on servers or to redistribute to lists, requires prior specific permission and/or a fee. Request permissions from Permissions@acm.org.

Copyright $\odot$ ACM 2019 2573-0142/2019/December - Article\#232 \$15.00

https://doi.org/10.1145/3361113 
such as routines, roles, and relationships [22]. This re-negotiation work is made difficult because it puts into question aspects of one's life that have come to be taken for granted.

Today, a lot of re-negotiation for transition work is taking place through different Information and Communication Technologies (ICTs), such as Facebook and other social media on mobile phones, through which people can engage in re-negotiation work while in transition. Earlier research within HCI and CSCW has showed how new mothers have utilized ICTs as a means through which to gain emotional support, yet little, if any, research has explicitly focused on renegotiation for transition work of mothers. To explore the use of ICTs for re-negotiation work, in this study we focus on the ICT practices of new mothers. New mothers are a unique set of people through which to explore the use of ICTs for re-negotiation work, in that their transition is both immediate and long term, they experience several physical and emotional disruptions at once, and must develop strategies to navigate through this new terrain. Life transitions often involve unlearning expectations associated with a previous role, while simultaneously learning expectations of a new role. There is a critical need to understand how to aid new mothers in the complexity of the transition experience, particularly considering the lack in current existing formal support mechanisms. After birth, new mothers for example, are not required to see a doctor for another 6 weeks post-partum. Home visits by health practitioners are not common practice in the United States, despite other countries successfully showing this to be beneficial for both mothers and child [13] [15] This gap in care has given rise to critical infrastructure, where women reappropriate ICTs or build new ICTs to create their own transition support systems, for example through Facebook groups focused solely on the experience and needs of new mothers [50] [68]. In this paper we try to answer the following research questions:

- How are ICTs used among new mothers to adapt to a range of issues while in transition?

- How do new mothers self-organize to develop new socio-technical infrastructures, what motivates the creation of these infrastructures, and what role do these infrastructures serve in the adaptation process?

This paper contributes to the emerging body of literature on new motherhood and use of ICTs, by providing a nuanced analysis of self-organization within social media groups, through critical infrastructure, in relation to new motherhood.

\section{RELATED LITERATURE}

\subsection{Identity Crisis in Transition Stemming from "Normative" Motherhood}

Life disruption, such as starting a new job, moving to a new town, or becoming a new mother, are often debilitating and rest primarily with the individuals and families that experience them. Disruptions such as this often upend former routines and expectations of daily life, which leaves a person with a new gap in their life that must be filled via a transition phase-a period of adjustment in which relationships, roles, and routines are re-negotiated to address changing circumstances. When a family moves to a new town, for example, what was once taken for granted can no longer be readily enacted or assumed; old routines are disrupted and new routines must be established, new relationships formed, new jobs found, and more.

When people undergo a transition, they often experience this process as a crisis of self-identity [20]. Our self-identity is what defines us as an individual; a strong sense of self-identity can give a 
person security in their daily lives [28]. Scholars contend that while one's self-identity feels very individuated, it is actually the product of interactions with others [45]. Goffman [23] further asserts that our identity matches elements of our context-that is, we develop our self-identities in relation to extant rules and norms within the social settings in which we are embedded. Our interrelationship with our social environment can be seen in the practice of impression management, in which people attempt to positively influence how they are viewed by others. This social interactionist view of self-identity underscores how much we, as individuals, are products of our relations with others and with society as a whole. Identity crises, in transition then, emerge as people are left feeling lost and questioning who they are in relation to new rules and norms relative to how they enact their self-identity [20].

To explore emergent identity crises amongst new mothers, in our study we draw on a feminist a perspective of identity. Feminist scholars have explored identity as a gendered identity construction. Prior to the women's movement, most accounts of gender focused on biological sex-a fixed binary construction of male and female. To deconstruct this man/woman binary, Judith Butler [12] described how gender is not a fixed identity; rather, gender is performative and we perform our gender by engaging in behaviors that are appropriate and consistent. We learn what is appropriate and consistent through conditioning and cultural representations, such as through the home environment and mass media. For example, in some cultural contexts, through the influence of the media like television and magazines, women learn that a certain style of dress, such as wearing makeup, is feminine. Thus, Butler argues that gendered performances are not entirely by choice, as enacting gender in an "incorrect" way can have negative implications for how one is perceived in society.

In the context of new motherhood, the identity of the "mother" is reflected in, and diffracted by, our engagement with the social world [[46]. That is, there are normative societal and cultural expectations of what it means to be a mother and how to enact a "motherly" identity that are generated from the media we consume (i.e. television shows), to the familial models we observed in our own childhoods, where women are often depicted as natural mothers who are also selfless and caring nurturers [67]. From the perspective of new mothers, then, there is an imagined ideal of what motherhood will be as observed through this engagement, that has been institutionalized. Yet what it means to be 'a good mother' in society, this imagined ideal, is in conflict with the reality that new mothers experience post-child birth. This conflict between the myth of motherhood and the reality of motherhood leads to a crisis of identity [16] whereby new mothers experience a form of cognitive dissonance as they are forced to mediate the ideal image of motherhood with reality. This dissonance begs for resolution, so people engage in re-negotiation work as a means of reconstructing their self-identities.

\subsection{The Systemic Marginalization of Mothers}

During a transition, re-negotiating self-identity can become a routine practice through which people learn to develop personal security. As a means of enacting routines, people often draw on infrastructure, which, traditionally conceived, is defined as the technical foundation, or basic framework, that underlies a large-scale system [37] [61]. When considered broadly, the roads and freeways we use to engage in travel are part of the infrastructure. Similarly, Internet networks allow us to regularly communicate with people across distance and time using digital devices like laptops. In shifting the perspective on what comprises infrastructure, computer scholars have 
developed the concept of information infrastructure. Primarily, the work of Hanseth and Lyytinen [26] develops the concept of information infrastructures, which are information systems that are integrated into communities through which people engage in information practices. As such, information infrastructures support information routines and enable people to routinely consume and produce information within institutions and communities, such as through Internet media like Instagram or Facebook.

Moreover, Star and Ruhleder [61], in their formative work, find that technical and social infrastructures are intertwined. That is, they describe how physical and technical infrastructures are interwoven with human organizations and relationships-or, the physical and technical infrastructures are actually enabled by humans [61]. This is what Lee, Dourish, and Mark [37] dub "human infrastructure", which is defined as the "arrangements of organizations and actors that must be brought into alignment in order for work to be accomplished". Unlike social networks, human infrastructures bring together both people we know, such as family and friends, as well as invisible actors, such as government institutions, and we as a society depend on human infrastructure to support our routines. For example, when we use the system of roads and freeways to travel, we do not always think about those who work behind the scenes to maintain the infrastructure, yet we rely on them to support this routine practice. In the event of a failure in infrastructure, however, the infrastructure (i.e. physical, technical, informational, human) becomes visible [37]. When this happens, the infrastructure is at the forefront of people's minds and activities. For example, when we suddenly lose connection to the Internet while watching shows on Netflix, we become aware of the presence of infrastructure, consisting of WiFi and Internet cables. This breaking down has also been addressed as "seamfulness" in several previous works [7] [66].

When considering people undergoing transition, however, the infrastructures that people may be relying on to support their re-negotiation work, may be failing them. As a means of further explicating this perspective, we turn to Star [60] who describes that, as a property of their invisibility, infrastructures often fade into the background and have the potential to mediate our experiences unknowingly, and even adversely. This is especially salient when we consider that infrastructures, like other systems, are designed by humans. Human beings have values and perspectives, and these values and perspectives can be biased and thus re-enforce existing norms and thus marginalize people undergoing transition. This view is important when we consider the ways in which infrastructure is used in re-negotiation work.

In the context of new mothers, existing infrastructures and infrastructural arrangements are often designed around gendered binaries. As a result, new mothers often suffer from a lack of support from their employers, healthcare networks, and spouses, especially after delivering a child [47], which can serve to complicate their ability to engage in re-negotiation work. Importantly, during pregnancy there are a number of formal and informal support mechanisms in place to support women through the process of becoming a mother [1]. For example, this support comes from medical providers like obstetricians and midwives, and through friends and family (i.e. baby showers). While many of these support structures come from privileged spaces, they are the 'ideal' prescribed through the formal support structures described above that women compare their lived experiences against. In all cases, the focus of these support mechanisms is in caring for the mother in order to ensure the best possible outcome: a healthy infant [42] [46]. However, many women 
experience a stark contrast in care once the baby is born. The focus shifts from caring for the infant by way of caring for the mother to caring for the infant directly. For example, formal support for maternity leave and childcare is often lacking. One of the main reasons women do not return to work after having children is the exorbitant cost of child care in the United States. As noted in a recent report [70], infant care in thirty-three states costs more annually than college tuition. Further, a family with a median household income spends, on average, $1 / 5^{\text {th }}$ of it to cover fulltime childcare for one child. For individuals making minimum wage, one child in fulltime childcare equates to $64 \%$ of their annual income [70]. As such, due to the combination of internal stressors (e.g. changes to identity) and external stressors (e.g. lack of support) after childbirth, women often suffer from a deep sense of loss, unreadiness, feelings of isolation [6], and depression [43]. There are formal infrastructures in place to ensure continuity of care for the infant, yet beyond a standard six-week postpartum visit with the obstetrician, most women lose a point of care [26] [46]. They are left largely alone to navigate this dramatic life event and identity shift.

This leads to the question of how new mothers might utilize technology to restructure their world and develop a means for re-negotiating their self-identities?

\subsection{Critical Infrastructure Supporting Re-Negotiation Work of New Mothers}

Research in CSCW and CHI has a long history in transition work. Scholarship exploring the role of ICTs during transition has explored residential moves [56] [57], breakups [41] [52] [69], domestic violence [17] [41], homelessness [14] [15] [41] [51], job loss [11], the transition from high school to college [56] [59], and gender transition [24]. These studies illustrate that people are using ICTs to navigate their transitions, though they examine only one transition at a time and do not have a central focus on how people re-negotiate conceptual relationships, such as their identities, as a means of successfully transitioning.

Moreover, from research on impression management in social media, we know that people commonly present different information depending on the audience [40] and engage in a variety of self-presentation strategies [30] [33] [34] [58]. This research suggests that people may be using multiple ICTs or different affordances within any given platform when engaging in re-negotiation work while in transition. For example, tools such as Facebook enable interaction with friends and family, and new mothers may not wish to engage with this audience, whereas they can connect with other mothers through private groups. As such, new mothers can develop new practices and gain resources that will help them re-negotiate their identities in transition and obtain support.

More specific to our domain of inquiry, scholarship on matrescence, the process of becoming a mother, has explored how women experience new motherhood, including experiences of: social exclusion of new mothers [22] and loss [6]. Fields such as nursing, midwifery, and child health have researched the role that technology plays in mothers' lives specifically [10] [35]. Most relevant to our study is work that has focused on the use of digital technologies by new mothers (e.g. [7] [22] [44] [50] [63] [64] [68]) and to a certain extent new fathers [2] [3] [4]. These studies illustrate that new mothers are using digital technologies to support their transition, specifically highlighting the information-seeking behaviors of new mothers in digital spaces [7] [22] and the use of anonymous online platforms to provide emotional outlets for mothers to 'vent' about their day-to-day experiences [68]. This research suggests that new mothers have previously used multiple digital technologies to support different facets of their transition as they renegotiate their identity as a mother. 
Given that the infrastructures that new mothers draw on while in transition can serve as further sources of disruption, we believe they can work around these issues by relying on alternative infrastructures or building new infrastructures in support of re-negotiation work. For example, Semaan and Mark [54] showed how through infrastructuring practice, when people live through chronic disruption as caused by war, they often create infrastructural alternatives, or build new infrastructures, as a means of maintaining routine practices when formal infrastructures through government agencies fail. Similarly, Semaan, Britton, and Dosono [53], in their exploration of veteran transitions, underscore how veterans are building bottom-up, inverse infrastructures that are counter to formal, institutionalized infrastructures, thus serving as a counter-narrative that reflects the real needs of the veteran population.

To explore this phenomenon, we again draw on Star [60], who describes infrastructure as the establishment and maintenance of elements that support something to be operated on. For example, a canal is part of the infrastructure that a farmer needs to water their crops. From the perspective of an engineer, maintaining the canal is a job. When there is a natural disaster, such as a flood, the canal becomes a potential threat to people's lives. This leads to the question proposed earlier by Star and Ruhleder [61]: "When is infrastructure?" The answer to this question is seen in the practice of infrastructuring-the intentional production of infrastructure by users as a means of achieving a particular goal. In this view, infrastructure is often defined in use and thus its properties are often aligned with the individuals and communities that design, maintain, and use it. Due to this dialectic nature of infrastructuring, infrastructure is continually shaped through an alignment between people and contexts.

Against this backdrop, we aim to explore the ways in which new mothers use and build digital infrastructures to engage in re-negotiation work. In the context of transitions, several online digital infrastructures exist, such as those available through Facebook groups, and the meaning of these infrastructures may change and new infrastructures can emerge, through an ongoing alignment between people and their needs in their respective contexts. The use of, and design of self-organized infrastructure, is typically associated with achieving a particular goal [19]. Previous work has explored the emergence and use of such infrastructures with respect to its support of repair work [29], its facilitation of mobile work [18], its promotion of civic engagement [31], its influence on IT design [48], and its ability to address infrastructural gaps [66].

In this paper, we argue that new mothers are using and creating critical infrastructures, which are conceptualized as digital and non-digital spaces through which people reflect on their own identities while also critiquing existing systems, related to parallel work [55]. In the context of the critical infrastructures being used and designed by new mothers, women are simultaneously renegotiating the ideals of motherhood while also critiquing the gendered norms that permeate their social worlds. To our knowledge, few studies exist that seek to uncover the infrastructure practices of women. For example, Fox, Uglado, \& Rosner [21] argue that feminist hackerspaces create opportunity for different values, goals, and practices than typically shape technology cultures. Our study builds on this work, where we posit that the re-appropriation of Facebook groups as a critical infrastructure is a feminist practice that works to create opportunity for different values, goals, and practices to shape the culture of new motherhood in a different way. In sum, ICTs can enable critical re-negotiation work in transition, which we illustrate here. 


\section{METHOD}

The study was conducted as a qualitative interview study; we performed hourlong semi-structured interviews with new mothers. The semi-structured interview protocol was designed as a life history asking new mothers about their lives before pregnancy, during pregnancy, and their experiences as new mothers. When investigating their experiences as new mothers-the transition phase-we asked people to describe their routines and general and identity-related issues they experienced. We asked them to describe their uses and adoption of ICTs as part of this process, as a means of understanding the role ICTs played in their transitions. Our questions in particular addressed how they found and joined the various groups they were members of, how they engaged with each group, what kind of things they posted (and why), and what types of relationships they formed within the groups. Further, we asked how the affordances of the groups design either supported or hindered their transition to new motherhood (secret vs. private groups, broad membership vs. specific criteria required for membership beyond motherhood, rules and methods of administration of the groups).

\subsection{Participants}

Participants were recruited through word-of-mouth, as well as snowball sampling. We interviewed twelve new mothers, all members of social media groups focusing on motherhood, such as year-of-birth groups, special characteristics of children groups, special life connection group (such as teachers or sorority members) and special life-circumstance motherhood groups (e.g. single parents). They were between the age of 33 and 42 and had between one and three children each, two were also pregnant. All had college degrees, and came generally from a social middle class; however, this was an effect from the recruitment method. Table 1 shows the details of the participants.

Table 1. Participant Overview

\begin{tabular}{|l|l|l|l|}
\hline & Age & Children & Partner status \\
\hline Participant 1 & 37 & 8 & Divorced/re-partnered \\
\hline Participant 2 & 41 & $6,9,12$ & Separated \\
\hline Participant 3 & 33 & 1,3 & Married \\
\hline Participant 4 & 39 & 1,5 & Separated \\
\hline Participant 5 & 33 & Pregnant, 8 & Divorced/re/married \\
\hline Participant 6 & 42 & 3 & Married \\
\hline Participant 7 & 39 & $2,5,6$ & Married \\
\hline Participant 8 & 36 & 3 & Single mother by choice \\
\hline Participant 9 & 40 & 11,21 & Married \\
\hline Participant 10 & 33 & 2,6 & Married \\
\hline Participant 11 & 35 & 2,5 & Married \\
\hline Participant 12 & 37 & Pregnant, 3, 7 & Divorced/re-partnered \\
\hline
\end{tabular}




\subsection{Analysis}

The interviews were analyzed using elements from grounded theory [62] in particularly open coding and categorization. After transcription, two researchers read through the interviews and developed concepts on the basis of the coded data material, which were later categorized. The concepts emerged from the data rather than being prescribed from the interview guide. These concepts and phenomena were compared in relation to their context, and broader categorization was agreed on between the two researchers. The analysis continued as a comparison between different findings in relation to the categorizations. This comparison of conceptualized data was performed to uncover the participants' main concerns and how they continually try to resolve them in relation to motherhood and their utilization and self-organization of online social media groups.

\section{FOUNDATION OF MOTHERHOOD: A LACK OF INSTITUTIONAL SUPPORT}

We now turn to our results where we first describe some of the foundations for new motherhood, as experienced and described by the participants. This foundation laid ground for a further description and analysis of the mothers' uses and practices around online social network groups.

Our participants, women who had all been transitioning into a new identity as mothers at one point, described how, in parallel with child birth, they in several cases felt lost and abandoned by the traditional infrastructures in place (doctors, nurses, family, workplaces). This is particularly salient given that, at the present moment, maternal death rates are on the rise in the United States. The rate of maternal death in the United States increased by $26.6 \%$ from 2000-2014 [39], in stark contrast to most other countries where the rate of maternal death is dropping almost as dramatically. It has been reported that one of the main causes of this increase is a lack of preparation and protocols for treatable maternal complications during childbirth [39]. That is, medical staff and personal are trained and prepared for treatable complications for infants, whereas care for mothers is of secondary concern.

Further, postpartum depression (PPD) is acknowledged by the medical community as one of the most common non-obstetric complications for childbearing women [46]. Often called the "baby blues', an infantilizing term for a serious medical condition, it may cause a woman to have difficulty bonding with her baby, loss of appetite, hopelessness, severe anxiety, inability to sleep, and recurrent thoughts of suicide. While it is acknowledged as one of the most common complications, one that typically begins within the first few weeks after childbirth, women rarely see a doctor until six weeks postpartum, where the focus is not on the woman as a whole person, but rather simply her physical recovery from the act of giving birth. Also, the diagnosis is often framed around the impact on the infants well-being, not the mother [45].

This was corroborated by our informants, who described how particularly, in the early days of new motherhood, they felt that they were unsupported. That is, they were left to negotiate their identity as a new mother without aid or assistance from formal care infrastructures. P3 for example describes a situation in the hospital after the birth of her first child:

[...] my husband came in afterwards and I was just sobbing hysterically because it was it was really scary and none of the nurses, nobody was there to help with the baby, it was just me and the baby alone and I couldn't touch her. (P3) 
Similarly, P1 for example describes how she felt very alone the first while, even years, as she did not receive any support from her family or friends:

[...] those first couple of weeks so [...], like my family could not come help from Europe so the first couple weeks it was just me and my husband and like I said [...] we were sort of alone in this town it was really just us and I, I felt like a complete zombie, I mean I just felt like I wanted to cry all the time and I couldn't really you know, I don't really feel like I was functioning and the hormones were all up and down and, uhm I found it to be really difficult. I realize this is a difficult experience for everybody I'm not saying I was special or anything. [...] I had a really tough time and truth be told I had a really tough time adapting and maybe I'm jumping ahead here and feel free to stop me if so but I had a very tough time with the first years of motherhood period. [...] And I felt very unprepared. I don't have any siblings, I don't have younger cousins. Like I said my friends hadn't really had kids. And the whole thing sort of hit me like a truck. (P1)

One topic that frequently emerged in our interviews was the lack of institutional and familial support for the mother herself post-childbirth. All of our informants described how they, with respect to different aspect, lacked support, specifically describing how prior to giving birth they were being constantly monitored, yet, post-childbirth, they were abandoned and felt alone:

I read this article, I think it was in NPR or the New York Times, I can't remember, but it described mother's who just gave birth as candy wrappers and it just totally matched my experience, you know? Like before you give birth you're constantly being monitored by doctors, everyone is making sure you're ok, asking how you're feeling, asking what you need, and then you have the baby and all of that focus shifts to the baby. It's almost like you get forgotten, like you were just this host, and it doesn't matter what you're feeling, what you're going through. Hell, once you leave the hospital you don't see the doctor again for over six weeks-I mean your body goes through incredible trauma to deliver a baby-this 8 pound bowling ball through your vagina, tearing it to bits, and nobody looks at you again for over a month. Forget how you feel emotionally. My mother-in-law came over and just asked 'aren't you so in love?!' and I wanted to scream. I'm hurting, I'm scared, I don't know what the hell I'm doing. Yes, of course I love my baby. But I'm also so freaking lost and scared and no one cares. Like you're just not supposed to talk about it. (P12).

Here, this informant uses the metaphor of a "candy wrapper" to describe her experiences as a new mother-that is, she felt that she was simply a vessel used to birth a child, and soon after giving birth, she was discarded and no longer cared for. However, all of our informants described adopting and using a range of secret "Mothers' groups" on Facebook, through which they could receive support and support others undergoing the transition into motherhood. We now turn to more detailed accounts of how these groups were utilized to navigate this new identity and the transition into motherhood.

\section{ONLINE MOTHERS' GROUPS AS CRITICAL INFRASTRUCTURE FOR TRANSITION INTO MOTHERHOOD}

Digital Mothers' groups have developed rapidly, over a fairly short time, from online email lists in the 90 s and early 2000 to purpose-built online forums to self-organized groups within Facebook, which is now one of the most widely adopted social media platform. Mothers' groups traditionally encompass face-to-face community groups; in some countries they are facilitated by health services, such as the United Kingdom-based "Deptford Model" [36] and the Australian "Earlybird Program" [32], most often initiated as public services in the late 80 s and early 90s with the acknowledgment that child-health and mother-health are inevitably intertwined. In the United States, however, no such system exists, apart from privately initiated communities, solely on behalf of the mothers' own initiatives. Commercial options for new mother community activities are often limited to paid options such as indoor playgroups (e.g. Gymboree) and mother/baby yoga. With the advent of the Internet, groups have initiated online, first as email groups [25] and more recently as subgroups of broader social media arenas [65]. With Facebook being a major 
player in broader social media, and its option for both "closed" and "secret" groups, a significant number of new mothers conjugate at special purpose mothers' groups. The difference between these and older online forums is the level of commercialization and level of moderation; Facebook affords self-organized groups of room for discussion, media sharing and a chosen level of openness to the public, where many previous online forums were often affiliated commercial products (e.g. What to expect, diapers brands) or were centrally moderated [8]. Our findings here illustrate how these online groups had become critical infrastructure in the transition work of the participant.

According to our participants, Mothers' groups, particularly on Facebook, had become integral components of their lives. Most of our participants were members of multiple groups, each serving a different purpose, meeting different needs, including information, advice, support, venting, solace, and connection. The types of groups varied, including 'garage sale' groups, what we call 'affinity groups', meaning groups where most members do not know each other personally but share a deep connection based on a mutual affiliation, including type of job/career, month of child's birth, marital status (e.g. single moms, same sex moms), child health issues; location based groups; and pre-motherhood friend groups who join together post-motherhood to share experiences (for example sorority sisters who created a mom group).

Most of our participants started with one group and then added more as they were made aware of/invited to additional groups. This happened in a few ways; for example, a mother might be part of a large affinity group and, in conversations/posts within this group becomes aware of splinter/offshoot groups with a more niche focus, or the mother searches for additional groups based on specific needs (help with car seat issues, breastfeeding, pumping at work, mothering differently-abled children, etc.). One participant described finding an age-based group through a different app she had been connected with during her pregnancy:

I had been on the What to Expect app, you know just tracking the pregnancy and what not, there was a little chat bit I didn't really like the way it was set up so I saw somebody mention in one of the posts that they had set up a Facebook group so I decided to join the Facebook group when he was probably three months old [...] that actually helped me find people who had babies, it was actually for people who had babies born in the same month as mine, so all of the babies were the same age and they're all sort of going through the same thing so everybody was bringing their own experiences of where they were and that actually really helped because I felt less alone. (P6)

In addition to age-based groups, a number of our participants joined groups based on location:

I'm in a couple buy-sell-trade groups, I'm in a local career mom's group-that one's really much more about supporting each other and really looking for a network of moms in my town that are going through the same kind of things and struggles being working parents [...] a lot of moms travel a lot and will post if they're at the airport and their flight got delayed and see if anyone else is in the airport to meet for a drink, or job postings [...]. (P3)

Other participants joined local place-based groups as a way to locate community resources:

For the local mom's groups it's mostly for the practical stuff: where are things going on, who's a good pediatrician, how do I get my kid in afterschool, with specialized groups are more for like who I am as opposed to where I live. (P4)

Another mother expressed the need to join a local group after moving to a new town and feeling isolated: 
I got involved when I moved to my new town and I was in this new community and I felt pretty isolated, I mean my husband was gone a lot and I lived kind of out a ways from everyone else, it was really hard for me... I wanted to get to know other moms... I wanted to find out kind of what was going on here cause it's very much like you have to go to events, there's not like a children's museum you can take your kids to, you gotta know like when there's going to be a petting zoo downtown so that you can have that experience with your child. (P4)

Two of our participants had actively created and managed a number of Facebook mothers' groups themselves. One participant decided to create an affinity group from a prior social group, her former sorority sisters. She notes:

I'm not sure where the motivation to start the group actually came from, I was always sort of the black sheep in the sorority, not the joiner, but we all have babies now and I decided to start it. I felt we were all in the same place starting out to be mommies and because I had so many questions I'm sure they had questions to, I wanted to start something because we're comfortable with each (sorority!) other to ask the odd questions-what's wrong with the color of my kids poop or whatever it happens to be kind of forum. I just wanted it to be an informal thing for us. (P8)

It was evident that these groups became so essential to our participants because they provided a place, created by and for women, to engage in deep identity re-negotiation work as they navigate their way from, between, and around their identities as both women and mothers. Specifically, we find that the use, re-appropriation, and creation of these spaces served as a way through which mothers were not only re-inventing themselves, but also critiquing gendered norms that permeate the infrastructures that have marginalized their identities as new mothers. Here, we describe this through the following themes: others like me; self-organized transition autonomy; and community migration tactics for sustaining personal safety.

\subsection{Others Like Me: Pushing Against Normative Expectations of Motherhood}

The normative expectations of motherhood, as manifested through media representations and other infrastructures, is one centered around the idea that women are to always be excited and happy about having a baby. That is, in their daily lives, women felt that they could not freely and openly describe the realities of their transition, their fears, concerns, and more. Particularly, our participants described feeling depressed and at times even ashamed at how they felt towards motherhood, where they were led to believe they were 'supposed' to feel elated and totally in love with their child. As P1 notes:

I think there is just a very high expectation of American mothers in terms of how they are supposed to feel, how much they're supposed to give, how much they're supposed to always be in mommy mode and not woman mode and not professional mode and not all the other identities that they have [...] I had a really tough time and truth be told, I had a really tough time adapting. (P1)

Further, P2 describes managing the difficulties of new motherhood as simply being something she had to 'suck up':

[...] this was my job, to just suck it up...(P2)

Mothers' groups allowed these women a place to ask engage in re-negotiation work by asking questions like 'Is this normal? Am I the worst mother for feeling this way?' and find validation, acceptance, and compassion. P2 described how the group she is most active in impacted her: 
[...] for me it has been way more about as a woman, changing my trajectory in life, getting some validation that like, I matter. (P2)

For all of our participants, mothers' groups became a safe space where they could feel less alone, where they could see others going through the same thing, a place to find solace and connection, as P6 described:

I felt more support and solace, you know women were going through the same things that I was and so that really, really, really helped actually. It still helps me to this day and he's two and a half. (P6)

Another participant explained relatedly:

I found the group and you know initially watching from afar at how these women who you know were in a very similar position that I was, how they were managing their lives, but it's been, it seems ridiculous to say it's a group where like I've never met $99 \%$ of these women but it has felt like these people understand what I'm going through in a way that is totally different than even my most well-meaning, thoughtful friends... I've felt like that group was critical for me, seeing other people not just doing it but ultimately thriving. (P2)

Through their participation in mothers' groups, however, new mothers were able to re-craft their sense of self and redefine what was normative, individually, as well as for the communities of mothers participating across these groups. That is, through their interactions with one another, they learned that while they were led to believe that being a mother was always a happy and joyous process, that in reality, it was okay if they felt unhappy about being a mother, or to question themselves and their evolving self-identity. This is was expressed most clearly by $\mathrm{P}$ :

I'm not a fan of Facebook at all. But one day, I used Facebook, just looking through it when I don't have anything to do, and I happened across a board... I'm not exactly sure how I happened across it, but it's for mother's with strong willed children and it has been an amazing place to go when you've had a bad day... you see there's other people going through totally the exact same story and use the exact same words you would use... it's more the moral support because when you see these other parents just in everyday life, who have it all together, and you know your kids just making you feel like you're crazy, making you feel like sometimes you just want to run away, that it's good to know that there's other people feeling the same way. (P9)

Similarly, for new mothers who wanted to continue pursuing their careers, they felt that established gendered norms were centered around them focusing their lives on motherhood and caring for their child, as opposed to being a mother and a mother with a self-fulfilling career. However, our informants, through their participation in, or creation of, mothers' groups, were pushing against these established norms. For example, P8, who created and managed four mother groups, started her first group out of a need for mentorship for her career. She was in a larger group that was focused on her field, yet whenever questions regarding how to be successful came up they were always focused on 'leaning in' and 'leaning on' a spouse or partner for child management. As a single-mother-by-choice (SMC) she was curious what single mothers in her field did to create success. In addition to this group, she launched one focused on strategic planning for mothers in her career field, one for vegetarian dinner planning, and then a fourth group for women considering becoming single mothers/divorcing. She notes that while she was an SMC and did not go through a divorce with children, she saw a need for this group emerging and offered to start it so that it existed to help those who needed it. Through their engagement in new mothers' groups on Facebook, our informants were on one hand able to engage in identity work, while also critically reflecting upon and critiquing established norms. 


\subsection{Self-Organized Transition Autonomy: Generating Material Support}

Our participants described how formal infrastructures and infrastructural arrangements often enforced norms of support in motherhood. Here, they described how they felt that it was normative to feel as though, in order to be a successful mother, they required a spouse or partner to help them emotionally and financially. This notion of spousal requirement was present in their everyday life.

However, through the use, re-appropriation, and creation of digital infrastructures, our informants were critiquing these gendered norms. That is, these online spaces allowed our participants to develop new norms around transition autonomy, through which women themselves could support one another in their transition to motherhood and beyond. Informants started to develop mechanisms, by design, in their online spaces to support a range of needs not met through formal infrastuctures.

Beyond emotional support, one critical element of support that emerged from many of these groups, according to our participants, was actual material support, such as buying and mailing presents, food, and other material goods as gestures of support for other new mothers. P6 notes an instance of support:

They're always raising money or sending meals or something. There's a little boy, an older brother of one of the twin's siblings who is 11 and he is bullied relentlessly, and she, you know, comes to the group all the time to talk about um how much he's been bullied and what they're doing to help stop it and all the mothers got together in the group and actually, cause he didn't get any Valentines, they all sent him Valentines and he opened up a big box full of Valentines from the toddlers and the mothers and he was really happy. (P6)

Similarly, informants created emergency financial support mechanisms within their own communities to assist mothers in need of immediate support. For example, this included quick responses to emergent financial needs. Some participants noted that groups they were in had created a pool of money, where every member had donated $\$ 10-20$ to be used in an emergency for a member. P12 explained:

We created this fund to help women who needed money quickly. We saw a few women trying to leave abusive relationships but couldn't because their husband controlled all the money-they had no way to get out. They posted to the group asking for advice on what to do to keep their kids safe and we were able to set up a GoFund me account and load it up. She got out, was able to find and pay for a lawyer, and get protections put in place for herself and her kids. We're a village and we take care of each other. We may not always agree on everything but we're all mamas trying our best to care for our kids and our careers. It isn't an easy road. (P12)

Here, our informants were organizing to generate support within their community, thus pushing against institutionalized and oppressive infrastructures, creating new pathways for support and success. The examples also illustrate how the intertwining of digital support and material support can strengthen the sense of cohesion within self-organized online groups.

\subsection{Tactics for Sustaining Personal Safety Against Normative Threats: Community Migration and Discontinuing Use}

While these mothers' groups met a wide range of needs for our participants; our informants described how their participation in certain mothers' groups could threaten their personal safety. 
For example, P1 described how she felt her posts, if in the wrong hands, could be used against her if made public:

Maybe it's because of my job but you have to remember nothing online is ever totally safe. I think twice before I post something that could be used against me in court related to custody of my kiddo. It's a process I think through before I post-if I were a judge, what would this look like? (P1)

Through deeper analysis, we find that people felt their personal safety was in jeopardy when they perceived normative threats-that is, when other participants were drawing on institutionalized norms to make judgements about other people's posts. One way in which these threats manifested was through the threat of outsiders who drew upon normative expectations of motherhood in guiding their interpretations of what was being disclosed in private mothers' groups. That is, in these cases, participants felt that outsiders were drawing on institutionalized norms when interpreting their posts, and thus felt the need to protect themselves. For example, P6 described a situation where a participant in one of the mothers' groups she was a part of was posting about her experiences with her baby. She was depressed and having a hard time with her baby, as opposed to being the "nurturing" and "caring" mother that conforms to normative expectations. Here, this informant describes how outsiders posed a threat:

One of the things, somebody posted screenshots and reported someone actually to CPS [child protective services] because that woman was having a very, very hard time with her second son who wouldn't stop crying. She would post a video of you know when she put the baby down, they would just cry, and she actually talked about the problems she was having with this new baby all the time, and how she hates her life and whatnot, so this other person thought that [she should] take a screenshot and actually reported her to CPS without letting the other woman know and whatnot because she was afraid that I guess she was going to do something to one of her children, which was definitely far from the case, I mean she was coming to this group for support which is what everyone else was giving her, support and letting her know she's not alone and giving her suggestions but, ummm she was reported and everyone found out who it was, this outsider, and she was removed from the group... So I think that shocked and scared a lot of people. (P6)

As a means of combatting these threats, informants described adopting a range of tactics through which they could limit threat and sustain their personal safety. On the one hand, participants described that, as they transitioned and their experiences and needs shifted, they often migrated to different mothers' groups. P4, for example, explains how she felt the need to move into a single mothers' group where she did not have to self-censor as much, after her ex-husband got arrested:

[I self-censor] a lot because it makes people uncomfortable, for one thing, uhm, and it's also something you can't really bring up easily in polite conversation. Uhm... [...] so when my uh... estranged husband was arrested I, I already knew there was like a single parents [in her profession] group, [...], I just remember being like wow, like there's this common theme in [broader mothers' group], that like you need to have this supportive, wonderful partner in order to make this happen, right, to have the career and the children. And I mean [my complicated situation] just kind of comes up over and over again. (P4)

Other participants described discontinuing the use of mothers' groups whereby the community members and the information being produced threatened their self-identity. P4, for example, in attempting to give birth to a child, suffered several miscarriages. In the context of normativity, women often choose to not disclose that they have experienced a miscarriage or miscarriages, as disclosing this sensitive, personal information, tends to present stigma [5]. That is, in our society, women are expected to only disclose only when they are successful in becoming pregnant, and not the many losses they may suffer. In her experiences, P4 found that the mothers' groups that focused on pregnancy threatened her well-being, leading her to discontinue use until she was later pregnant: 
...and I actually stopped following that page when I was trying to get pregnant after the miscarriage and dealing with miscarriages just because so many people were posting about pregnancy and it was just too upsetting... and then when I had a successful pregnancy I started going back. (P4)

Overall, however, despite these threats to their personal safety and well-being, all of our participants noted that these groups played an integral role in their lives and they viewed them differently from other types of online groups they belonged to. As P8 noted:

I can't say this for sure, but in general, the othering groups [as opposed to the general facebook groups], can be a 180-like $99 \%$ of the time people are supportive, mothers are in general more helpful and I often think to myself that I'm thankful I had my son because these women have helped me in so many other ways, I would never have had that without being a mom. (P8)

As we have seen, participants used online mothers' groups for a range of purposes in terms of support and negotiation of normative behavior in relation to their identity building. While they were not feeling supported through traditional infrastructures, the online infrastructure often provided another type of comfort and encouragement. We now turn to our discussion where we look at the repurposing of the online structures, that the mothers were doing in more detail.

\section{DISCUSSION}

While online social media today is widely used for a multitude of purposes and reasons, taking a closer look at how new mothers re-design, re-appropriate and self-organize online groups to their needs of emotional support, contributes with valuable insights into the building of socio-technical infrastructure. With new, unpredicted emotional responses and lack of information about many small details in relation to motherhood, the mothers sought reaffirmation of their new feelings and issues related to the motherhood transition. Drawing on feminist design principles [13], we found that the mothers were designing and repurposing these online forums to heal, empower, and sustain their experience of matrescence. While the mothers did not design the technical tools and social media platforms themselves, they appropriated the platforms in order to re-design their experience as women and mothers in society. We discuss each action in turn.

\subsection{Healing By Design}

The participants confirmed our scholarly framing that they did not receive much care immediately after birth. While the unborn child and mother received adequate medical care, once the baby was born the focus shifted almost solely to the baby and the baby's experience. The women felt an immediate point of loss, both with no longer being pregnant and the intensive shift in focus from her care to that of the infant. Many of them identified a 'reality shock' that occurred as they went through labor and into the first few weeks of parenthood. They identified that the reality of becoming a mother was often nothing like what they imagined and expressed a deep sense of loss, guilt, shame, and anger that was impossible to discuss with their partners or family members for fear of being judged. For example, while it is not uncommon according to nursing and medical literature for new mothers to take some time to form an emotional bond with their infant, some of the new mothers we spoke with expressed fear and guilt for not feeling 'so in love' with their infant the moment they were born. The self-organized social media groups created by mothers and for mothers, became a safe space to find support in filling this gap. They were able to start the process of healing from this shock of new motherhood and modify their own understanding of it, 
by designing a different kind of social infrastructure within the online space. Feminist design principles seek to use collaborative and creative practices to address the deepest challenges a community faces [13]. For new mothers, these challenges are multilayered and complex, including a need to heal physically and emotionally. Mothers found that they could use these spaces as a first point of contact in managing their transition. That is, these spaces were designed to help mothers heal from matrescence, by creating a safe space to ask questions, over finding out what levels of 'feeling low' are okay before contacting health professionals, to actually being able to share personal factors that they cannot share with people of a face-to-face pre-established relationship. It is widely acknowledged that people are more likely to share sensitive information within anonymous contexts [38]. Further, mothers were comfortable asking questions about the health of their baby (for example, finding remedies for diaper rash) and asking for help with their own physical recovery from childbirth, where they were able to provide detailed, graphic explanations of issues they were facing. When talking about postpartum depression, finding that they were not alone in their experience, while also getting feedback on the different types of treatments others had used and the impact of these treatments, such as impacting the ability to breastfeed.

\subsection{Empowered Through Design}

All of the mothers in our study identified a changed family dynamic and expressed anxiety, frustration, and confusion navigating this shift. The transition to motherhood was never expected to be easy, but participants often expressed how they were surprised with the characteristics of the changes. For example, some mothers expressed frustration about their spouses or partners offering "to help" with the baby. While the women acknowledged that the desire to help is well intentioned, it made them realize that from both a societal and hyper-local perspective (their partner/spouse), the baby was their job, their responsibility. Additionally, the offer of the coparent "to help" required the new mother to have an answer and if she did not know what was needed, either for the baby or herself, she was left to struggle through alone. Without articulating it directly, they found that they suddenly had to live up to society's perception of motherhood, which was also confirmed through their online interactions, yet, many mothers found ways of negotiate identity building through communication with others in the same transformation context. The online groups created a place for the mothers to empower themselves, not only by gaining insights into other's similar struggles, but also in finding a critical support structure of human beings-other mothers-who were 'there'. For example, through the design of these groups, mothers were able to unite and offer immediate financial support, empowering a member to leave an abusive husband at a critical moment. The infrastructure that the women had created within the group allowed them to quickly identify an immediate need. One woman created a gofund me page, posted it back in the group, and raised thousands of dollars within hours. This money paid for a lawyer to file a restraining order, first month's rent for an apartment, as well as providing emotional support and check-ins. Women were empowered through the design of these groups to actively create change, to support the lived-experiences of individual members.

\subsection{Sustained By Design}

The online interaction within mothers' groups was also used as a critical infrastructure for managing stress during the transition. All of the mothers expressed a loss of self, where they felt that becoming a mother had forever changed them in deeply complex ways and that they sometimes missed who they were before having a child. The mothers were careful to say that they 
did not regret having the child, but rather they did not realize how much of themselves they would be required to 'give up' to become a mother. This includes their work life, their physical appearance, and their relationships with their partners and friends. Our participants described the incredible difficulty they faced while trying to operate within the boundaries of 'good motherhood', where they felt it was expected that they lead almost solely child-focused lives. Rich [49] defines 'good motherhood' or the 'natural mother' as "... person without further identity, one who can find her chief gratification in being all day with small children, living at a pace tuned to theirs" (p.22). The mothers we spoke with experienced intense stress over the cognitive dissonance they encountered in enacting their new identity of 'mother'. They expressed anger at the freedom they lost by becoming a mother and shame for admitting that they missed who they were before they had children. The mothers discovered that matrescence, the process of becoming a mother, did not have an end. While they healed from the physical trauma of childbirth, found recovery from postpartum depression, and began to 'settle in' to motherhood, they realized there were new challenges that would continue to emerge as their children grew older and relationships changed. This lead to the necessity of longer term sustained online spaces. For example, one of the participants was actively involved in the group started while she was pregnant around the birth month/year. Her child was now three years old, and these women had supported each other and sustained each other across those years. At times, these groups offer a place to vent, to blow of steam, to find solace. The online spaces have become integrated and a point of daily connection, supported by the generic characteristic of the Facebook online network. The demands of the idealized motherhood identity do not disappear as the baby becomes a toddler, child, or teenager; rather they shift and take on new, and often oppressive forms. The mothers' experiences of cognitive dissonance, as they were forced to mediate this ideal image of motherhood with reality, lead them to engage in motherhood on their own terms, no matter the age and stage of the children. Online mothers' groups, as experienced by our participants, made it possible for mothers to see, account for, and find remedies to the very unequal burdens and benefits that parenthood distributes in society.

\section{CONCLUSION}

In the context of our interview data, we see new mothers creating and using online groups to reflexively re-craft their identities, and provide support to challenge the isolating social norms while also providing strategies to work through and move beyond them. In our study, we also saw new mothers working to critique and subvert the formal support services and social norms that are most troubling, for example, developing awareness and support for postpartum depression and support for mental health care through the transition to motherhood. While previous work in this space has emphasized the social support these online media can provide, our study explicate broader issues of lacking care of mothers, that contribute to the necessity of these, often secret forums. We found that mothers re-appropriate these online spaces and design them to do what American society does not-support mothers. In an essay published on Motherly, Beth Barry [9] writes: "It takes a village, but there are no villages ... [mama,] you and I are not the problem at all. WE ARE DOING PLENTY. We may feel inadequate, but that's because we're on the front lines of the problem, which means we're the ones being hardest hit. We absorb the impact of a broken, still-oppressive social structure so that our children won't have to. That makes us heroes, not failures." [9]. We suggest that women are designing these critical infrastructures to become a new kind of village, not limited by location and family, but rather expansive and inclusive, working, on a grass-roots level, to create change, to empower women, and to sustain support across time. 


\section{ACKNOWLEDGMENTS}

We thank the participants for their time. This study was supported by the National Science Foundation under grant \#1657429. Any opinions, findings, and conclusions or recommendations expressed in this material are those of the authors and do not necessarily reflect the views of the NSF. Supplemental support was provided by Ithaca College and Mozilla Research.

\section{REFERENCES}

[1] G. Affleck, H. Tennen, J. Rowe, B. Roscher, and L. Walker. 1989. Effects of formal support on mothers' adaptation to the hospital-to-home transition of high-risk infants: The benefits and costs of helping. Child Dev. (1989), 488-501.

[2] Tawfiq Ammari and Sarita Schoenebeck. 2015. Understanding and Supporting Fathers and Fatherhood on Social Media Sites. In Conference on Human Factors in Computing Systems, 1905-1914.

[3] Tawfiq Ammari and Sarita Schoenebeck. 2016. "Thanks for your interest in our Facebook group, but it's only for dads": Social Roles of Stay-at-Home Dads. In ACM Conference on Computer-Supported Cooperative Work \& Social Computing, 1363-1375.

[4] Tawfiq Ammari, Sarita Schoenebeck, and Silvia Lindtner. 2017. The Crafting of DIY Fatherhood. In Proceedings of the 2017 ACM Conference on Computer Supported Cooperative Work and Social Computing, 1109-1122.

[5] Nazenin Andalibi and Andrea Forte. 2018. Announcing pregnancy loss on Facebook: A decision-making framework for stigmatized disclosures on identified social network sites. In Proceedings of the 2018 CHI Conference on Human Factors in Computing Systems, 158.

[6] L Barclay, L Everitt, F Rogan, V Schmied, and A Wyllie. 1997. Becoming a mother: An analysis of women's experience of early motherhood. F. Adv. Nurs. 25, 4 (1997), 719-728. DOI:https://doi.org/10.1046/j.1365-2648.1997.t01-11997025719.x

[7] Louise Barkhuus and Valerie Polichar. Empowerment through seamfulness: smart phones in everyday life. Personal and Ubiquitous Computing 15, no. 6 (2011): 629-639

[8] Louise Barkhuus, Elizabeth Bales, and Lisa Cowan. 2017. Internet Ecologies of New Mothers: Trust , Variety and Strategies for Managing Diverse Information Sources Optional phone number Abstract. 50th Hawaii Int. Conf. Syst. Sci. (2017), 2283-2292.

[9] Beth Barry. 2016. In the absence of 'the village,' mothers struggle most. Motherly. Retrieved from https://www.mother.ly/life/in-the-absence-of-the-village-mothers-struggle-most

[10] Jay M Bernhardt and Elizabeth M Felter. 2004. Online pediatric information seeking among mothers of young children: results from a qualitative study using focus groups. F. Med. Internet Res. 6, 1 (2004).

[11] Moira Burke and Robert Kraut. 2013. Using Facebook after losing a job: Differential benefits of strong and weak ties. In Proceedings of the 2013 Conference on Computer Supported Cooperative Work, 1419-1430.

[12] Judith Butler. 1988. Performative acts and gender constitution: An essay in phenomenology and feminist theory. Theatr. 7. 40, 4 (1988), 519-531.

[13] Sasha Costanza-Chock. 2018. Design justice: Towards an intersectional feminist framework for design theory and practice. In Proceedings of the Design Research Society.

[14] Christopher A Le Dantec and Keith W. Edwards. 2008. Designs on dignity: Perceptions of technology among the homeless. In Proceedings of the SIGCHI Conference on Human Factors in Computing Systems, 627-636.

[15] Christopher A Le Dantec, Robert G Farrell, Jim E Christensen, Mark Bailey, Jason B Ellis, Wendy A Kellogg, and Keith W. Edwards. 2011. Publics in practice: Ubiquitous computing at a shelter for homeless mothers. In Proceedings of the SIGCHI Conference on Human Factors in Computing Systems, 1687-1696.

[16] Hans Peter Dietz. 2013. Pelvic floor trauma in childbirth. Aust. New Zeal. f. Obstet. Gynaecol. 53, 3 (2013), $220-230$.

[17] Jill P Dimond, Casey Fiesler, and Amy S Bruckman. 2011. Domestic violence and information communication technologies. Interact. Comput. 23, 5 (2011), 413-421.

[18] Ingrid Erickson and Mohammad Jarrahi Hossein. 2016. Infrastructuring and the challenge of dynamic seams in mobile knowledge work. In Proceedings of the 19th ACM Conference on Computer-Supported Cooperative Work \& Social Computing, 1323-1336.

[19] Ingrid Erickson and M.H. Jarrahi. 2016. Infrastructuring and the challenge of dynamic seams in mobile knowledge work. In Proceedings of the 19th ACM conference on Computer-Supported cooperative work \& social computing, 13231336.

[20] Erik H Erikson. 1994. Identity: Youth and crisis. WW Norton, New York.

[21] Sarah Fox, Rachel Rose Ulgado, and Daniela K Rosner. 2015. Hacking Culture , Not Devices: Access and Recognition in Feminist Hackerspaces. (2015).

[22] Lorna Gibson and Vicki L Hanson. 2013. 'Digital Motherhood': How Does Technology Support New Mothers? CHI '13 Proc. SIGCHI Conf. Hum. Factors Comput. Syst. (2013), 313-322. DOI:https://doi.org/10.1145/2470654.2470700

PACM on Human-Computer Interaction, Vol. 3, No. GROUP, Article 232, Publication date: December 2019. 
[23] Erving Goffman. 1959. The presentation of self in everyday life. Doubleday, New York.

[24] Oliver L Haimson, Jed R Brubaker, Lynn Dombrowski, and Gillian R Hayes. 2015. Disclosure, stress, and support during gender transition on Facebook. In Proceedings of the 18th ACM Conference on Computer Supported Cooperative Work \& Social Computing, 1176-1190.

[25] W Hall and V Irvine. 2009. E-communication among mothers of infants and toddlers in a community-based cohort: A content analysis. F. Adv. Nurs. 65, 1 (2009), 175-183.

[26] O Hanseth and K Lyytinen. 2010. Design theory for dynamic complexity in information infrastructures: the case of building internet. f. Inf. Technol. 25, 1 (2010), 1-19.

[27] T. Harris, G. W. Brown, and A Bifulco. 1986. Loss of parent in childhood and adult psychiatric disorder: The role of lack of adequate parental care. Psychol. Med. 16, 3 (1986), 641-659.

[28] Herminia Ibarra and Jennifere L. Petriglieri. 2010. Identity work and play. F. Organ. Chang. Manag. 23, 1 (2010), 10-25.

[29] Steven J Jackson. 2014. Rethinking Repair. Media Technol. Essays Commun. Mater. Soc. (2014), 221-239.

[30] Pamela Karr-Wisniewski, D Wilson, and H Richter-Lipford. 2011. A new social order: Mechanisms for social network site boundary regulation. In Americas Conference on Information Systems, 1-8.

[31] M. Korn and A Voida. 2015. Creating friction: infrastructuring civic engagement in everyday life. In Proceedings of The Fifth Decennial Aarhus Conference on Critical Alternatives, 145-156.

[32] Sue Kruske, Virgina Schmied, and Margaret Cook. 2007. The 'Earlybird'gets the breastmilk: findings from an evaluation of combined professional and peer support groups to improve breastfeeding duration in the first eight weeks after birth. Matern. Child Nutr. 3, 2 (2007), 108-119.

[33] Airi Lampinen, Vilma Lehtinen, Asko Lehmuskallio, and Sakari Tamminen. 2011. We're in it together: Interpersonal management of disclosure in social network services. In Proceedings of the SIGCHI Conference on Human Factors in Computing Systems, 3217-3226.

[34] Airi Lampinen, Sakari Tamminen, and Antti Oulasvirta. 2009. All my people right here, right now: Management of group co-presence on a social networking site. In Proceedings of the ACM 2009 International Conference on Supporting Group Work, 281-290.

[35] Margareta Larsson. 2009. A descriptive study of the use of the Internet by women seeking pregnancy-related information. Midwifery 25, 1 (2009), 14-20.

[36] Nicky Leap. 1993. Helping you to make your own decisions: Antenatal and postnatal groups in Deptford, South East London. In Birth International.

[37] Charlotte P. Lee, Paul Dourish, and Gloria Mark. 2006. The human infrastructure of cyberinfrastructure. In Proceedings of the 2006 20th Anniversary Conference on Computer Supported Cooperative Work, 483-492.

[38] Xiao. Ma, Nazanin Andalibi, Louise Barkhuus, and Mor Naaman. 2017. People are either too fake or too real: opportunities and challenges in tie-based anonymity. In Proceedings of the 2017 CHI Conference on Human Factors in Computing Systems, 1781-1793.

[39] Nina Martin. 2017. U.S. Has The Worst Rate Of Maternal Deaths In The Developed World. NPR. Retrieved from https://www.npr.org/2017/05/12/528098789/u-s-has-the-worst-rate-of-maternal-deaths-in-the-developed-world

[40] Alice E Marwick and Dannah Boyd. 2011. I tweet honestly, I tweet passionately: Twitter users, context collapse, and the imagined audience. New Meida Soc. 13, 1 (2011), 114-133.

[41] Michael Massimi, Jill P Dimond, and Christopher A Le Dantec. 2012. Finding a new normal: the role of technology in life disruptions. In Work, Proceedings of the ACM 2012 Conference on Computer Supported Cooperative, 719-728.

[42] NS Mauthner. 1998. Reassessing the importance and role of the marital relationship in postnatal depression: methodological and theoretical implications. f. Reprod. Infant Psychol. 16, (1998), 159-183.

[43] NS Mauthner. 1999. Feeling low and feeling really bad about feeling low: women's experiences of motherhood and postpartum depression. Candian Psychol. 40, (1999), 141-161.

[44] B.T. McDaniel, S.M. Coyne, and E.K Holmes. 2012. New Mothers and Media Use: Associations Between Blogging, Social Networking, and Maternal Well-Being. Matern. Child Health f. 16, 7 (2012), 1509-17.

[45] George Herbert Mead. 1934. Mind, self and society. University of Chicago Press, Chicago.

[46] Paula Nicolson. 1999. Loss, happiness, and postpartum depression: The ultimate paradox. Can. Psychol. Can. 40, 2 (1999), 162.

[47] Paula Nicolson. 2000. Competing explanations of postpartum depression: what are the benefits to women? In Women's health contemporary international perspectives. BPS Books, Leicester.

[48] Matt Ratto. 2011. Critical Making: Conceptual and Material Studies in Technology and Social Life. Inf. Soc. 27, 4 (July 2011), 252-260. DOI:https://doi.org/10.1080/01972243.2011.583819

[49] Rich, Adrienne. 1995. Of woman born: Motherhood as experience and institution. WW Norton \& Company.

[50] Meredith Ringel Morris. 2014. Social networking site use by mothers of young children. In Proceedings of the 17th ACM conference on Computer supported cooperative work \& social computing, 1272-1282.

[51] Jahmeilah Roberson and Bonnie Nardi. 2010. Technology use among the homeless. In Proceedings of the 2010 ACM Conference on Computer Supported Cooperative Work, 445-448. 
[52] Corina Sas and Steve Whittaker. 2013. Design for forgetting: Disposing of digital possessions after a breakup. In Proceedings of the SIGCHI Conference on Human Factors in Computing Systems, 1823-1832.

[53] Bryan Semaan, Lauren M. Britton, and Bryan Dosono. 2016. Transition Resilience with ICTs: 'Identity Awareness' in Veteran Reintegration. In Proceedings of the ACM Conference on Human Factors in Computing Systems.

[54] Bryan Semaan and Gloria Mark. 2011. Technology-mediated social arrangements to resolve breakdowns in infrastructure during ongoing disruption. ACM Trans. Comput. Interact. 20, 18 (2011), 1-21.

[55] Bryan Semaan and Ingrid Erickson. Critical Infrastructuring as a Tactic for Transition Recovery: Designing as Healing. In submission to Transactions on Computer-Human Interaction.

[56] Irina Shklovski, Robert Kraut, and Jonathon Cummings. 2006. Routine patterns of internet use \& psychological wellbeing: Coping with a residential move. In Proceedings of the SIGCHI Conference on Human Factors in Computing Systems, 969-978.

[57] Irina Shklovski, Robert Kraut, and Jonathon Cummings. 2008. Keeping in touch by technology: Maintaining friendships after a residential move. In Proceedings of the SIGCHI Conference on Human Factors in Computing Systems, 807-816.

[58] Manya Sleeper, Rebecca Balebako, A Sauvik Das, J mber Lynn McConahy, Ason Wiese, and Lorrie Faith Cranor. 2013. The post that wasn't: Exploring self-censorship on facebook. In Proceedings of the 2013 Conference on Computer Supported Cooperative Work, 793-802.

[59] Madeline E Smith, Duyen T Nguyen, Charles Lai, Gilly Leshed, and Eric P Baumer. 2012. Going to college and staying connected: Communication between college freshmen and their parents. In Proceedings of the ACM 2012 Conference on Computer Supported Cooperative Work, 789-798.

[60] Susan Leigh Star. 1999. The ethnography of infrastructure. Am. Behav. Sci. 7, 1 (1999), 111-134.

[61] Susan Leigh Star and Karen Ruhleder. 1996. Steps toward an ecology of infrastructure: Design and access for large information spaces. Inf. Syst. Res. 7, 1 (1996), 111-134.

[62] A. Strauss and J. Corbin. 1998. Basics of qualitative research: Techniques and procedires of developing grounded theory. Sage, Thousand Oaks, CA.

[63] Austin L. Toombs, Kellie Morrissey, Emma Simpson, Colin M Gray, John Vines, and Madeline Balaam. 2018. Supporting the Complex Social Lives of New Parents. In In Proceedings of the 2018 CHI Conference on Human Factors in Computing Systems.

[64] Diego Trujillo-Pisanty, Abigail Durrant, Sarah Martindale, Stuart James, and John Collomosse. 2014. Admixed portrait: reflections on being online as a new parent. In Proceedings of the 2014 conference on Designing interactive systems, 503512.

[65] Valtchanov, B.L., D.C. Parry, T.D. Glover, and C.M. Mulcahy. 2014. Neighborhood at your fingertips: Transforming community online through a Canadian social networking site for mothers. Gend. Technol. Dev. 18, 2 (2014), 187-217.

[66] Janet Vertesi. 2014. Seamful spaces: Heterogeneous infrastructures in interaction. Sci. Technol. Hum. Values 39, 2 (2014), 264-284.

[67] A Woollett and H Marshall. 2000. Motherhood and Mothering. In Women's health contemporary international perspectives. BPS Books, Leicester.

[68] Sarita Yardi Schoenebeck. 2013. The Secret Life of Online Moms: Anonymity and Disinhibition on YouBeMom.com. In Proceedings of the International AAAI Conference on Weblogs and Social Media, 555-562.

[69] Svetlana Yarosh and Gregory D Abowd. 2011. Mediated parent-child contact in work-separated families. In Proceedings of the SIGCHI Conference on Human Factors in Computing Systems, 1185-1194.

[70] Valentina Zarya. 2016. Think College Is Expensive? In Most States, Child Care Costs Even More. Forbes. Retrieved from http://fortune.com/2016/09/28/child-care-costs/

Received March 2019; revised June 2019; accepted September 2019. 